\title{
ASSOCIATION OF SEXUAL BEHAVIOURS AND PREMATURE EJACULATION
}

\author{
Nguyen Hoai Bac ${ }^{1,}$, Hoang Long ${ }^{2}$ \\ ${ }^{1}$ Hanoi Medical University \\ ${ }^{2}$ Hanoi Medical University hospital
}

Premature ejaculation (PE) is the most common reported sexual complaint in men. It is believed that PE is associated with sexual behavior such as early sexual experience, novelty of partners or frequencies of intercourse. Therefore, to examine the association of PE and sexual behaviors in men, a case-control study was conducted with a total of 418 clients Subjects were interviewed for general health status, sexual behaviors, IELT and requested to complete the premature ejaculation diagnostic tool (PEDT). DSM-IV-TR criteria were applied for the diagnosis of PE. Those who diagnosed with $P E(+)$ and PEDT score $\geq 11$ belonged to the PE group; those diagnosed with PE(-) and PEDT < 11 belonged to the non-PE group. The results indicated that no significant difference was noted regarding demographic features in the 2 groups. Normal men had a more frequent sexual life compared with PE patients $(9.71 \pm 6.09$ and $6.62 \pm 5.44$ episodes of sexual intercourses per month, respectively with $p<0.001$. Subjects who were single or circumcised had higher prevalence of $P E$ than married or uncircumcised men. Multivariable logistic analysis elucidated that circumcision, number of lifetime sexual partners and sexual frequencies were associated factors of PE. In conclusion, PE is a common sexual dysfunction in men. It was found to be significantly associated with circumcision and frequencies of sexual intercourse. Medical history taking of PE patients should include these sexual behavior factors.

Keywords: Premature ejaculation, sexual behavior

\section{INTRODUCTION}

Premature ejaculation (PE) is one of the most common sexual dysfunction in men. Although the epidemiologic data of PE varies between different cultural and geographic populations, the prevalence of PE is estimated to be $16-31 \%$ in multinational surveys. ${ }^{1,2}$ $\mathrm{PE}$ is not only associated with emotional and relationship distress, interpersonal difficulties and dissatisfaction in sexual life of the man but

Corresponding author: Nguyen Hoai Bac,

Hanoi Medical University

Email: nguyenhoaibac@hmu.edu.vn

Received: 19/02/2021

Accepted: 08/04/2021 also his partner. ${ }^{3}$

In 2014, the International Society of Sexual Medicine (ISSM) committee had agreed on an evidence based definition of PE, in which PE is characterized by: (i) ejaculation that always or nearly always occurs prior to or about within 1 minute of vaginal penetration (lifelong PE) or a significant and bothersome reduction in latency time, often to about 3 minutes or less (acquired $\mathrm{PE}$ ), (ii) the inability to delay ejaculation on all or nearly all vaginal penetrations and (iii) negative personal consequences, such as distress, bother, frustration and/or avoidance of sexual intimacy. Clinicians were advised to take into account other associated factors in 
the diagnosis of PE such as age, lifestyle and sexual behaviors. However, the mechanism of the correlation remained unknown.

Previous studies had implied that marital status, frequency of sexual intercourse and early sexual experience can affect the duration of the excitement phase of a man. ${ }^{5}$ On the other hand, the distress and frustration feedback from PE can lead to diminished self-esteem and confidence in sexual performance which further impair the ability to control ejaculation. Nevertheless, to our best knowledge, their relations with PE were only mentioned in demographic data without detailed investigation. Furthermore, the majority of the studies were conducted in Western community, which was fundamentally different from Asian countries regarding sensitive problem such as PE. Therefore, the aim of our study was to examine the association of sexual behaviors and PE.

\section{METHODS}

\section{Research subjects}

Clients who presented to the Andrology and Sexual Medicine Units of Hanoi Medical University Hospital from October 2018 to December 2019.

Inclusion criteria:

- Hetero sexual men between 16 and 64 years old.

- Men who were sexually active (have at least one sexually intercourse for the last 3 months)

- Have adequate information of sexual habits and PE condition.

Exclusion criteria: Men with concomitant erectile dysfunction, alcohol or drug abuse and mental illness.

\section{Method}

Study design: A case-control study.

Sampling method: Convenience sampling.
Study process: All clients who visited the department were invited and explained the purpose of the study and who agreed to participated in this study signed the inform consent. Eligible subjects were interviewed for PE condition based on DSM-IV-TR criteria and the translated premature ejaculation diagnostic tool (PEDT), a self-administered questionnaire which was developed and validated by Symond et al. Subsequently, 210 subjects who diagnosed with PE $(+)$ with PEDT score equal to or greater than 11 were selected into the PE group and 208 subjects diagnosed with PE (-) with PEDT less than 11 were selected into the control group. The remaining subjects were excluded from data analysis.

Participants were also requested to answer a questionnaire about general health status, marital status, comorbidities and sexual behaviors including frequency of sexual intercourse (defined as the number of sexual intercourses per month), frequency of masturbation (defined as the number of masturbation per month), number of sexual partners and time of the first sexual experience.

\section{Data analysis}

Descriptive analyses were used to summarize characteristics. The results were demonstrated as mean \pm standard deviation, median, min, max or number (percentage). Difference between 2 groups was calculated using independent T-student test for variables with standard normal distribution or Wilcoxon sign rank test for asymmetrical variables. The chi-square test was used to compare categorical data.Correlations between variables were evaluated with logistic regression model for categorical variables.

All hypothesis testing was considered statistically significant if $p<0.05$. Data was processed and analyzed using the $\mathrm{R}$ software version 3.6 .0 software. 


\section{Ethics}

The participation of all subjects was completely voluntary. All information of the participants was confidential. The study was approved by the Board of Directors of Hanoi Medical University Hospital.

\section{RESULTS}

Table 1. Demographic features of recruited subjects

\begin{tabular}{|c|c|c|c|}
\hline & Control $(n=208)$ & $P E(n=210)$ & $\mathbf{p}$ \\
\hline Age (year) & $30.83 \pm 6.76$ & $30.61 \pm 8$ & 0.57 \\
\hline $16-29$ & $100(48.08 \%)$ & $110(50.24 \%)$ & 0.61 \\
\hline $30-40$ & $88(42.31 \%)$ & $79(37.62 \%)$ & \\
\hline$>40$ & $20(9.62 \%)$ & $21(9.81 \%)$ & \\
\hline BMI $\left(\mathrm{kg} / \mathrm{m}^{2}\right)$ & $23.04 \pm 2.41$ & $22.28 \pm 2.25$ & 0.0035 \\
\hline \multicolumn{4}{|l|}{ Smoking } \\
\hline Yes & $163(78.37 \%)$ & $155(73.81 \%)$ & 0.275 \\
\hline No & $45(21.63 \%)$ & $55(26.19 \%)$ & \\
\hline Penile length (stretched) (cm) & $13.69 \pm 1.16$ & $13.27 \pm 1.28$ & 0.0005 \\
\hline Average testicular volume (mL) & $13.45 \pm 3.95$ & $13.67 \pm 3.65$ & 0.84 \\
\hline Testosterone level & $16.05 \pm 6.01$ & $17.69 \pm 5.87$ & 0.0026 \\
\hline Low (< $8 \mathrm{nmol} / \mathrm{L})$ & $11(5.29 \%)$ & $6(2.86 \%)$ & 0.208 \\
\hline Normal ( $\geq 8 \mathrm{nmol} / \mathrm{L})$ & $197(94.71 \%)$ & $204(97.14 \%)$ & \\
\hline
\end{tabular}

The mean age of the PE group and the control group was similar (30.83 \pm 6.76 and $30.61 \pm 8$ years, respectively). Although there were significant differences in BMI, penile length (stretched) and mean testosterone level between the two group $(p<0.05)$; however, the differences in the mean value of the aforementioned factors were negligible. No difference was found regarding smoking status and average testicular volume in PE men compared with normal men.

Table 2. Sexual characteristics of the subjects

\begin{tabular}{lccc}
\hline & Control $(\mathbf{n}=\mathbf{2 0 8})$ & PE $(\mathbf{n}=\mathbf{2 1 0})$ & p \\
\hline Marital status & & & \\
\hline Yes & $149(54.78 \%)$ & $123(45.22 \%)$ & 0.005 \\
\hline No & $59(40.41 \%)$ & $87(59.59 \%)$ & \\
\hline Period of sexual experience (year) & $9.26 \pm 6.71$ & $9.19 \pm 6.47$ & 0.9 \\
\hline Masturbation & & & \\
\hline Yes & $23(43.4 \%)$ & $30(56.6 \%)$ & 0.321 \\
\hline No & $185(50.68 \%)$ & $180(49.32 \%)$ & \\
\hline
\end{tabular}




$$
\text { Control }(n=208)
$$

$3.32 \pm 2.16$

$$
\text { PE }(n=210)
$$

$3.35 \pm 2.53$

0.5
Masturbation frequency

(episodes per month) *

\section{Circumcised}

\begin{tabular}{lccc}
\hline \multicolumn{1}{c}{ Yes } & $9(27.27)$ & $24(72.73)$ & 0.007 \\
\hline No & $199(51.69 \%)$ & $186(48.31)$ & \\
\hline $\begin{array}{l}\text { Number of sexual partners } \\
\text { Median (Min-max) }\end{array}$ & $3.04 \pm 2.47$ & $2.69 \pm 2.34$ & 0.026 \\
\hline 1 & $3(1-20)$ & $2(1-12)$ & 0.034 \\
\hline$>1$ & $58(42.34 \%)$ & $79(57.66 \%)$ & \\
\hline $\begin{array}{l}\text { Sexual intercourse frequencies } \\
\text { (episodes per month) }\end{array}$ & $150(53.38 \%)$ & $131(46.62 \%)$ & $<0.001$ \\
Median (Min-max) & $9.58 \pm 6.19$ & $6.66 \pm 4.87$ & \\
\hline
\end{tabular}

${ }^{*}$ Excluding men who have never masturbated

The number of episodes of sexual intercourse in one month of the PE group and the control group were $6.66 \pm 4.87$ and $9.58 \pm 6.19$, respectively $(p<0.001)$. Significant differences were found regarding marital status and the condition of the prepuce. Single or circumcised subjects were more likely to suffer from PE than married or uncircumcised men. The data also demonstrated that the number of sexual partners of both group were $3.04 \pm 2.47$ and $2.69 \pm 2.34$ female partners, respectively.

\section{Table 3. Associated factors of PE}

\begin{tabular}{ccccccc}
\hline & \multicolumn{3}{c}{ Univariable } & \multicolumn{3}{c}{ Multivariable } \\
\hline Associated factors & OR & $\mathbf{9 5 \%} \mathbf{C l}$ & $\mathbf{p}$ & OR & $\mathbf{9 5 \%} \mathbf{C l}$ & $\mathbf{p}$ \\
\hline Age & & & & & & \\
\hline $16-30$ & Reference & & & Reference & \\
\hline $30-40$ & 0.81 & $0.54-1.22$ & 0.33 & 0.96 & $0.58-1.59$ & 0.88 \\
\hline$>40$ & 0.95 & $0.48-1.86$ & 0.89 & 1.13 & $0.51-2.49$ & 0.75 \\
\hline Marital status & & & & & & \\
\hline Single & Reference & & & Reference & & \\
\hline Married & 0.56 & $0.38-0.81$ & 0.005 & 0.71 & $0.42-1.2$ & 0.2 \\
\hline Masturbation & & & & & & \\
\hline Yes & 1.34 & $0.75-2.39$ & 0.323 & 1.44 & $0.76-2.75$ & 0.26 \\
\hline No & Reference & & & Reference & & \\
\hline
\end{tabular}




\begin{tabular}{|c|c|c|c|c|c|c|}
\hline \multirow[b]{2}{*}{ Associated factors } & \multicolumn{3}{|c|}{ Univariable } & \multicolumn{3}{|c|}{ Multivariable } \\
\hline & OR & $95 \% \mathrm{Cl}$ & $\mathbf{p}$ & OR & $95 \% \mathrm{Cl}$ & $\mathbf{p}$ \\
\hline \multicolumn{7}{|l|}{ Circumcised } \\
\hline Yes & 2.85 & $0.15-0.77$ & 0.009 & 3.04 & $1.33-6.9$ & 0.008 \\
\hline No & Reference & & & Reference & & \\
\hline \multicolumn{7}{|l|}{ Sexual Partner } \\
\hline$\leq 2$ & 1.72 & $1.17-2.57$ & 0.006 & 1.61 & $1.05-2.5$ & 0.03 \\
\hline$>2$ & Reference & & & Reference & & \\
\hline \multicolumn{7}{|c|}{ Age of first sexual experience } \\
\hline$\leq 21$ & Reference & & & Reference & & \\
\hline$>21$ & 0.99 & $0.96-1.02$ & 0.82 & 0.87 & $0.55-1.35$ & 0.535 \\
\hline
\end{tabular}

Frequency of sexual intercourse / month

\begin{tabular}{lcccccc}
\hline More than 12 & Reference & \multicolumn{5}{c}{ Reference } \\
\hline $8-11$ & 2.14 & $1.25-3.68$ & 0.005 & 1.92 & $1.09-3.38$ & 0.023 \\
\hline $4-7$ & 2.65 & $1.51-4.65$ & 0.001 & 2.4 & $1.32-4.37$ & 0.004 \\
\hline Less than 4 & 4.09 & $2.28-7.32$ & $<0.001$ & 3.46 & $1.83-6.52$ & $<0.001$ \\
\hline
\end{tabular}

In single logistic regression model, PE was found to be significantly associated with marital status, circumcision, number of sexual partner and frequency of sexual intercourse. Single men and fewer intercourses per month were risk factors for PE. Particularly, subjects with less than 4 sexual intercourses per month were 4.09 times more likely to suffer from PE than the group of more than 12 intercourses per month $(p<0.001)$. We also found that the condition of the prepuce was associated with PE where circumcised men were more likely to have $\mathrm{PE}$ than men with intact prepuce $(\mathrm{OR}=3.62, \mathrm{p}<0.001,95 \% \mathrm{Cl} 1.78-7.34)$. However in multivariable logistic regression model, only circumcision status and sexual intercourse frequency were associated factors of PE. Masturbation and the age of first sexual experience did not contribute to PE.

\section{DISCUSSION}

The etiology of rapid and uncontrolled ejaculation in PE men remained largely unknown. Postulated explanations included lack of awareness in physical arousal due to early experience or infrequent sexual activity. ${ }^{5}$ However, data from previous studies were conflicted and the matter remained controversial. ${ }^{6,7}$ In this study, subjects in PE group and control group were similar in age. Subjects in each group had identical period of sexual experience which were also identical which was appropriate to further compare the sexual behavior effect to PE.

In a large community based survey in Korea, men with PE showed lower libido and frequency of sexual intercourse compared with non-PE men. ${ }^{8}$ Similar results were noted in an observational epidemiological study of PE among Italian men where PE patients had significantly decreased attempts of sexual intercourse. ${ }^{9}$ In our study, the mean episode of 
sexual intercourse per month in PE group was $6.48 \pm 5.4$ episodes, which is significantly lower than in control group $(9.71 \pm 6.09$ episodes per month, $p<0.001)$. Logistic regression analysis also demonstrated that subjects with infrequent sexual activity report higher chance of PE. Men with less sexual intercourses (< 12 episodes per month) were more likely to suffer from PE compare to the group who had regular coitus. This effect was most transparent in sub-group with less than 4 sexual intercourses in a month $(\mathrm{OR}=4.09, \mathrm{p}<0.01,95 \% \mathrm{Cl} 1.83$ - 6.52). Our results were consistent a previous study which also noted that infrequent sexual intercourse contributed to PE. ${ }^{6,10}$ In PE patients, the deficient sexual performance in return resulted in low self-confidence and anxious anticipation of a possible failure. In consequences, these men tended to avoid sex with their partner and therefore worsen their ejaculatory control. This process was described as the "Vicious cycle" by Jannini et al. ${ }^{11}$

Marital status was also found to be significantly associated with $\mathrm{PE}$ in single logistic regression model. In contrast to data from Verze et al study, ${ }^{9}$ our study suggested that single men were more likely to have PE than married men. It is understandable that patients who had a stable relationship found it easier to share their problem more often with their partners. Similar finding was also illustrated in Son et al where the rate of $\mathrm{PE}$ was lower in couple who openly discuss about their sexual life. ${ }^{10}$ However, in multivariable logistic regression model, this association was diminished. Therefore, the result implied that the effect of marital status on PE was confounded by other factors. Further studies are needed to confirm this.

In addition, we also found that the number of sexual partner had a relation with PE. The result indicated that subjects with 2 or less sexual partner had a greater odds of PE (OR $=1.61,95 \% \mathrm{Cl}=1.05-2.5)$. It was probably the result of $P E$ rather than the cause of $P E$ due to the fact that men with short ejaculatory time tended to have diminished self-confidence in establishing a new relationship. It can be implied that a man sexual function was refected by the number of his partner.

Further more, our result demonstrated that the condition of the prepuce was associated factor of PE. This finding was in agreement with a study of Kim et al where uncircumcised men had slightly longer IELT than in circumcised men. ${ }^{12}$ The loss of fine-touch neuroreceptor in the removed skin is assumed to be responsible for the absence of ejaculatory trigger. Therefore, circumcised men were unable to voluntarily control the moment of ejaculation. ${ }^{13}$ In a multinational study to assess the ejaculatory latency time in general male population, Waldinger et al also concluded that no difference in the median of IELT between cirucmcised and uncircumcised men. ${ }^{14}$ In our study, circumcised men were 3.04 times more susceptible to PE than uncircumcised men ( $p$ $<0.001,95 \% \mathrm{Cl}=1.33-6.9)$. This evidence suggested that circumcision was unable to improve PE condition. This result is consisted with a study of Tang et al. where circumciced men reported higher rate of $\mathrm{PE}(\mathrm{OR}=2.56$, $95 \% \mathrm{Cl}=1.43-4.54){ }^{6}$

In Eastern countries, masturbation is considered a risk factor for PE. A national survey in Korea showed that masturbation had an association with $\mathrm{PE}(\mathrm{OR}=1.48,95 \% \mathrm{Cl}=1.08$ 2.03). ${ }^{15}$ The majority of men who complained of PE believed they had excessive masturbation at a younger age. However, in our study, masturbation frequency did not differ between control group and PE group. No significant difference was found in the risk of PE in subjects 
who have masturbated. In fact, clinicians had utilized masturbation as a therapeutic treatment to help the man familiarize with the sensation of sexual arousal.

There were few limitations in our study. First, our results were unable to determine whether the subject had lifelong PE or acquired PE. Because different sub-types of PE sometimes require different strategies of treatment, ${ }^{16}$ further evaluation was needed in order to achieve the optimal outcome for each patient. Second, despite the proof that relational and marital problems were both the cause and the consequence of $\mathrm{PE},{ }^{11}$ the female partner was not included in the study.

\section{CONCLUSION}

$\mathrm{PE}$ is a common sexual dysfunction in men. It was found to be significantly associated with circumcision, number of lifetime sexual partner and frequency of sexual intercourse. Medical history taking of PE patients should include these sexual behavior factors.

\section{REFERENCES}

1. Laumann EO, Nicolosi A, Glasser DB, et al. Sexual problems among women and men aged 40-80 y: prevalence and correlates identified in the Global Study of Sexual Attitudes and Behaviors. Int J Impot Res. 2005; 17(1): 3957.

2. McMahon CG, Lee G, Park JK, Adaikan PG. Premature ejaculation and erectile dysfunction prevalence and attitudes in the AsiaPacific region. J Sex Med. 2012; 9(2): 454-465.

3. Althof SE. Prevalence, Characteristics and Implications of Premature Ejaculation/Rapid Ejaculation. Journal of Urology. 2006; 175(3): 842-848.

4. Serefoglu EC, McMahon CG, Waldinger $M D$, et al. An evidence-based unified definition of lifelong and acquired premature ejaculation: report of the second international society for sexual medicine ad hoc committee for the definition of premature ejaculation. Sex Med. 2014; 2(2): 41-59.

5. Masters W, Johnson VE. Human sexual inadequacy. Boston: Little, Brown. 1971.

6. Tang WS, Khoo EM. Prevalence and correlates of premature ejaculation in a primary care setting: a preliminary cross-sectional study. J Sex Med. 2011; 8(7): 2071-2078.

7. Strassberg DS, Kelly MP, Carroll C, Kircher JC. The psychophysiological nature of premature ejaculation. Arch Sex Behav. 1987; 16(4): 327-336.

8. Lee SW, Lee JH, Sung HH, et al. The prevalence of premature ejaculation and its clinical characteristics in Korean men according to different definitions. Int J Impot Res. 2013; 25(1): 12-17.

9. Verze P, Arcaniolo D, Palmieri A, et al. Premature Ejaculation Among Italian Men: Prevalence and Clinical Correlates From an Observational, Non-Interventional, CrossSectional, Epidemiological Study (IPER). Sex Med. 2018; 6(3): 193 - 202.

10. Son H, Song SH, Kim SW, Paick JS. Self-reported premature ejaculation prevalence and characteristics in Korean young males: community-based data from an internet survey. $J$ Androl. 2010; 31(6): 540 - 546.

11. Jannini EA, Carosa E, Pepe M, Lombardo F, Lenzi A. Update on Pathophysiology of Premature Ejaculation: The Bases for New Pharmacological Treatments. EAU-EBU Update Series. 2006; 4(4): 141-149.

12. Kim D, Pang MG. The effect of male circumcision on sexuality. BJU Int. 2007; 99(3): 619-622.

13. O'Hara K, J OH. The effect of male circumcision on the sexual enjoyment of the 
female partner. BJU int. 1999 (83): 79-84.

14. Waldinger MD, Mclntosh J, Schweitzer $\mathrm{DH}$. A five-nation survey to assess the distribution of the intravaginal ejaculatory latency time among the general male population. J Sex Med. 2009; 6(10): 2888-2895.

15. Song $\mathrm{WH}$, Yoo S, Oh S, et al. Ten-Year Interval Changes in the Prevalence of SelfIdentified Premature Ejaculation and Premature Ejaculation Based on an Estimated Intravaginal
Ejaculation Latency Time of $<3$ Minutes in the General Population: The Korean Internet Sexuality Survey (KISS) 2016. J Sex Med. 2019; 16(4): 512-521.

16. Waldinger MD, Schweitzer DH. The use of old and recent DSM definitions of premature ejaculation in observational studies: a contribution to the present debate for a new classification of PE in the DSM-V. J Sex Med. 2008; 5(5): 1079-1087. 